\title{
Effect of quercetin 7-rhamnoside on glycochenodeoxycholic acid-induced L-02 human normal liver cell apoptosis
}

\author{
SHUANG LIANG, WEI-WEI SU, YONG-GANG WANG, WEI PENG, YI-CHU NIE and PEI-BO LI \\ Key Laboratory of Gene Engineering of the Ministry of Education, Guangdong Key Laboratory of Plant Resources, \\ School of Life Sciences, Sun Yat-sen University, Guangzhou, Guangdong 510275, P.R. China
}

Received March 12, 2013; Accepted June 3, 2013

DOI: 10.3892/ijmm.2013.1414

\begin{abstract}
Quercetin 7-rhamnoside (Q7R) is one of the main flavonoid components of Hypericum japonicum. However, whether Q7R is one of the active ingredients responsible for the hepatopreventive effects of Hypericum japonicum has not yet been ascertained. Thus, the aim of the present study was to elucidate whether Q7R attenuates apoptosis induced by glycochenodeoxycholic acid (GCDC) in vitro, and to elucidate the mechanisms involved. L-02 human normal liver cells were pre-incubated with $0,50,100$ and $200 \mu \mathrm{M}$ Q7R for $30 \mathrm{~min}$ and then exposed to $100 \mu \mathrm{M}$ GCDC for the indicated periods of time. Methylthiazolyldiphenyl-tetrazolium bromide (MTT) was performed to examine cell viability. Apoptosis was evaluated by Hoechst 33258 staining and Annexin V-FITC/PI double staining. Intracellular reactive oxygen species (ROS) were detected by flow cytometry using the oxidation-sensitive fluorescent probe, DCFH-DA. The assay for glutathione (GSH) was performed using a GSH detection kit. Intracellular $\mathrm{Ca}^{2+}$ concentration was evaluated using a confocal laser scanning microscope with Fluo-3 as the $\mathrm{Ca}^{2+}$ probe and mitochondrial membrane potential $(\Delta \psi \mathrm{m})$ was measured by rhodamine 123 (Rh123) fluorescence. Q7R attenuated the GCDC-induced reduction in cell viability and the high apoptotic rate. Moreover, Q7R protected the L-02 cells from ROS overproduction, GSH depletion, intracellular $\mathrm{Ca}^{2+}$ accumulation and $\Delta \psi \mathrm{m}$ decrease induced by GCDC. These results suggest that Q7R attenuates L-02 cell injury induced by GCDC, possibly by inhibiting the overproduction of ROS, GSH depletion, intracellular $\mathrm{Ca}^{2+}$ accumulation and $\Delta \psi \mathrm{m}$ decrease, thereby minimizing L-02 cell apoptosis.
\end{abstract}

Correspondence to: Dr Pei-Bo Li, Key Laboratory of Gene Engineering of the Ministry of Education, Guangdong Key Laboratory of Plant Resources, School of Life Sciences, Sun Yat-sen University, 135 Xingang West Street, Haizhu, Guangzhou, Guangdong 510275, P.R. China

E-mail: lipb73@yahoo.com.cn

Key words: quercetin 7-rhamnoside, glycochenodeoxycholic acid, apoptosis, L-02 human normal liver cells

\section{Introduction}

Cholestasis, which is characterized by an impairment of bile formation and/or bile flow, is a commonly occurred pathophysiological process in certain liver diseases (1). The persistence of cholestasis and the retention of toxic bile salts in hepatocytes are associated with acute and chronic liver failure, leading to biliary fibrosis, cirrhosis and cancer $(2,3)$. The accumulation of hydrophobic bile acids (e.g., glycine conjugates of chenodeoxycholic acid) in the liver is considered to be an important factor contributing to hepatic injury $(4,5)$. In healthy individuals, the portal vein serum total bile acid concentration is approximately $20 \mu \mathrm{M}$; in patients with cholestasis, concentrations can reach $300 \mu \mathrm{M}(6)$. Toxic bile salts induce hepatocellular death through 2 mechanisms: necrosis at higher concentrations $(\geq 250 \mu \mathrm{M})(7,8)$ and apoptosis at lower concentrations $(\leq 100 \mu \mathrm{M})(9,10)$. Both types of cell death seem to play a role in cholestatic liver injury. The mechanisms involved in the toxicity of toxic bile salts include disrupting cell membrane integrity through their detergent action on lipid components (11) and triggering the generation of reactive oxygen species (ROS), which may eventually cause hepatocyte apoptosis or necrosis (12). Glycochenodeoxycholic acid (GCDC) is formed in the liver and acts as a detergent to solubilize fats for absorption. It is the predominant human dihydroxy bile salt under cholestatic conditions and is a likely candidate for bile acid-mediated hepatocellular injury during cholestasis due to its direct cytotoxic effects on hepatocytes (13). GCDC may cause hepatocyte apoptosis by activating the death receptor or by inducing oxidative damage that causes mitochondrial dysfunction, which subsequently triggers apoptosis $(12,14)$. Therefore, GCDC-induced hepatocyte apoptosis is a reliable and reproducible model, which is widely used to study the mechanisms involved in cholestatic liver injury.

In traditional Chinese medicine, Hypericum japonicum has been used for centuries as a raw material for herbal tea and for the treatment of cholestasis, as well as acute and chronic hepatitis (15). Quercetin 7-rhamnoside (Q7R; molecular weight, 448.377) is one of the main flavonoid components of Hypericum japonicum (16). It has been reported that Q7R possesses strong anti-porcine epidemic diarrhea virus activity, which is not simply due to its general action as an antioxidant (17,18). Amani et al reported that Schouwia thebaica Webb extracts containing Q7R significantly exert curative effects on carbon tetrachloride $\left(\mathrm{CCl}_{4}\right)$-induced liver injury in 
rats (19). However, whether Q7R is one of the active ingredients responsible for the hepatopreventive effects of Hypericum japonicum has not yet been ascertained. Thus, the aim of the present study was to determine the role of Q7R in GCDCinduced apoptosis in L-02 cells and to elucidate the possible mechanisms involved.

\section{Materials and methods}

Extraction and isolation of Q7R. Q7R (98.3\% purity) was extracted and purified from the herb, Hypericum japonicum. Briefly, a Hypericum japonicum sample was pulverized to a powder. One kilogram of powder was extracted by reflux with 101 distilled water 3 times ( $2 \mathrm{~h}$ for each repetition). The mixture was filtered and collected. The extract was then concentrated to 1.21 and then 4.51 aqueous ethanol $(95 \%)$ were added to the extract and stored at $4^{\circ} \mathrm{C}$ for $12 \mathrm{~h}$. The extract was then filtered and concentrated by rotary vaporization at $60^{\circ} \mathrm{C}$ under reduced pressure and $400 \mathrm{ml}$ residue was obtained. The residue was then redissolved in water (total volume $1,000 \mathrm{ml}$ ), which was added into a glass column $(6.0 \times 80 \mathrm{~cm}$, containing $1.0 \mathrm{~kg}$ polyamide resin). In the polyamide resin column chromatography, water and different concentrations of aqueous ethanol (20 and 60\%) were tested by a gradient elution program and aqueous ethanol $(60 \%)$ elution was collected. The elution fractions were united and then concentrated by rotary vaporization at $60^{\circ} \mathrm{C}$ under reduced pressure. The precipitate was filtered and washed with water and absolute ethyl alcohol, respectively and was then dried at $80^{\circ} \mathrm{C}$ for $1 \mathrm{~h}$. Q7R was obtained, and identification was performed by ultraviolet-visible spectroscopy (UV/Vis), electron spray ionization-mass spectrometry, proton nuclear magnetic resonance $\left({ }^{1} \mathrm{H}-\mathrm{NMR}\right)$ and carbon-13 nuclear magnetic resonance $\left({ }^{13} \mathrm{C}-\mathrm{NMR}\right)$ spectroscopy. Based on spectral analysis, the purified compound was verified as Q7R (19). The chemical structure of Q7R is shown in Fig. 1. The purity analysis was performed on a Waters 600 HPLC chromatography system (Waters Corp., Milford, MA, USA) with an Agilent C18 column ( $5 \mu \mathrm{M}, 250 \times 4.0 \mathrm{~mm}$ ID) purchased from Agilent Technologies, Inc. (Santa Clara, CA, USA). The mobile phase was prepared by mixing solvents, methanol: $2.5 \%$ (v/v) acetic acid (36:64 v/v), and the $\mathrm{pH}$ was adjusted to 2.5 with acetic acid. The detection wavelength and column temperature were set at $255 \mathrm{~nm}$ and $30^{\circ} \mathrm{C}$, respectively. The flow rate was $0.4 \mathrm{ml} / \mathrm{min}$. The loading volume was $3 \mu \mathrm{l}$. The purity of Q7R was $98.3 \%$. In this study, Q7R was dissolved in dimethyl sulfoxide (DMSO; Sigma, St. Louis, MO, USA) for treatment.

Cell culture. The L-02 human normal liver cells were a kind gift from professor Wen Chen (School of Public Health, Sun Yat-sen University, Guangzhou, China). The cells were cultured at $37^{\circ} \mathrm{C}$ (with $5 \% \mathrm{CO}_{2}$ and $95 \%$ humidity) in Dulbecco's modified Eagle's medium (DMEM) supplemented with $10 \%$ fetal bovine serum (FBS) (both from Gibco/Invitrogen, Carlsbad, CA, USA), $1 \%$ penicillin and $1 \%$ streptomycin. The following day, the medium was replaced with fresh DMEM and the cells were divided into 5 groups. Untreated L-02 cells in the first group served as the controls. Treated L-02 cells were stimulated with $100 \mu \mathrm{M}$ GCDC (Sigma) in the presence or absence of Q7R at the indicated concentrations and periods or time. The stock solutions of Q7R were prepared in DMSO. The final maximum concentration of DMSO in the experimental medium did not exceed $0.1 \%$.

Cell viability assay. Cell viability was evaluated by methylthiazolyldiphenyl-tetrazolium bromide (MTT) assay as previously described (20). The L-02 cells were seeded into 96-well plates at a density of 7,500 cells/well with $100 \mu \mathrm{l}$ DMEM medium per well and incubated for $24 \mathrm{~h}$. In the present study, the cells were pre-treated with various concentrations of Q7R $(0,50,100$ and $200 \mu \mathrm{M})$ for $30 \mathrm{~min}$ and subsequently exposed to GCDC $(100 \mu \mathrm{M})$ or the vehicle for an additional $24 \mathrm{~h}$. MTT (Sigma) was then added to each well followed by incubation at $37^{\circ} \mathrm{C}$ for $4 \mathrm{~h}$. Following incubation, the medium containing MTT was removed and $150 \mu \mathrm{l}$ DMSO were added. The optical density of the homogenous purple solutions was measured using a microplate reader (Mk3; Thermo Labsystems, Chicago, IL, USA) at $590 \mathrm{~nm}$. The optical density of the formazan formed in the control (medium only) cells was taken as $100 \%$ viability.

Detection of apoptosis assay by Hoechst 33258 staining. Following treatment as described above, the cells in 24-well plates were rinsed 3 times with phosphate-buffered saline (PBS) and stained with Hoechst 33258. Subsequently, the L-02 cells were viewed immediately by detecting fluorescence (excitation at $380 \mathrm{~nm}$ and emission at $460 \mathrm{~nm}$ ) under a fluorescence microscope (Nikon TE2000) and the images were recorded for later analysis. The morphological features of apoptosis were evident, including chromatin condensation, nuclear fragmentation and apoptotic body formation.

Detection of apoptosis assay by flow cytometry using Annexin V-FITC/PI double staining. The occurrence of apoptosis and/or necrosis was evaluated by Annexin V binding and PI uptake as previously described (21). The positioning of the quadrants on the Annexin V/PI dot plots was performed and living cells (Annexin $\mathrm{V}^{-} / \mathrm{PI}^{-}$), early apoptotic/primary apoptotic cells (Annexin $\mathrm{V}^{+} / \mathrm{PI}^{-}$), late apoptotic/secondary apoptotic cells (Annexin $\mathrm{V}^{+} / \mathrm{PI}^{+}$) and necrotic cells (Annexin $\mathrm{V}^{-} / \mathrm{PI}^{+}$) were distinguished. Therefore, the total apoptotic cell population included the percentage of cells with fluorescence Annexin $\mathrm{V}^{+} /$ $\mathrm{PI}^{-}$and Annexin $\mathrm{V}^{+} / \mathrm{PI}^{+}$staining. Annexin $\mathrm{V}$ binding was performed using an Annexin V-FITC kit (Invitrogen) according to the instructions of the manufacturer. Following treatment as described in above, the cells were harvested and washed with PBS and suspended in $100 \mu 1$ Annexin V binding buffer. The cells were then double stained with $10 \mu \mathrm{l}$ Annexin V and $5 \mu \mathrm{l}$ PI solution. The samples were incubated for $20 \mathrm{~min}$ at room temperature and then analyzed by flow cytometry (Gallios Flow Cytometer; Beckman Coulter, Brea, CA, USA).

Analysis of intracellular ROS levels by flow cytometry. The production of intracellular ROS was monitored by flow cytometry using an oxidation sensitive fluorescent probe (DCFH-DA; Beyotime, Shanghai, China). The cells were pre-treated with various concentrations of Q7R $(0,50,100$ and $200 \mu \mathrm{M})$. Thirty minutes later, GCDC $(100 \mu \mathrm{M})$ was added to the medium followed by incubation at $37^{\circ} \mathrm{C}$ for an additional $12 \mathrm{~h}$. When the medium was removed, the cells were harvested and washed twice with PBS. The cells were then incubated with 


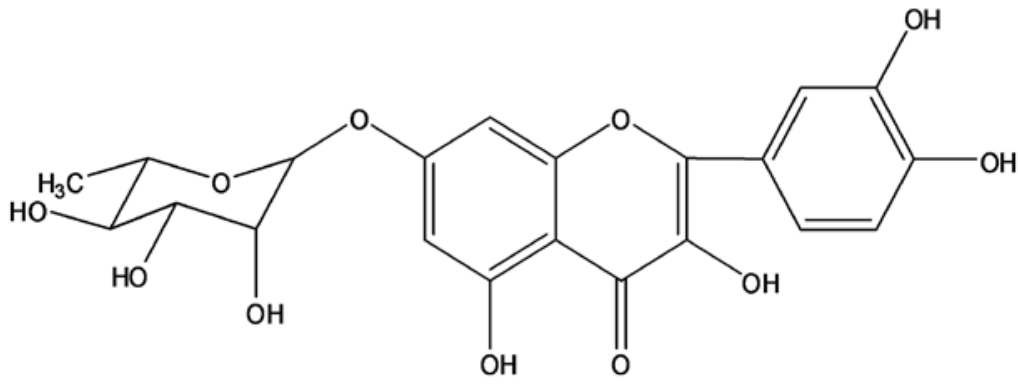

Figure 1. Chemical structure of quercetin 7-rhamnoside (Q7R).

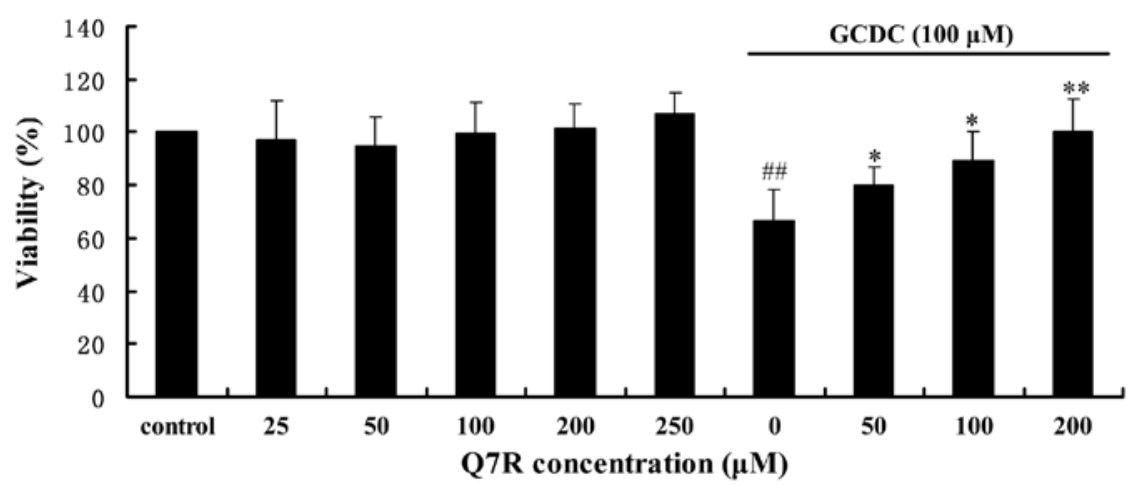

Figure 2. Protective effects of quercetin 7-rhamnoside (Q7R) on glycochenodeoxycholic acid (GCDC)-induced cytotoxicity in L-02 cells. Cell survival rate was evaluated by MTT assay. Each value represents the mean $\pm \mathrm{SD}$ of 3 individual experiments. ${ }^{\sharp \#} \mathrm{P}<0.01$ compared to control cells. ${ }^{*} \mathrm{P}<0.05$, ${ }^{* * *} \mathrm{P}<0.01$ compared to treatment with GCDC alone.

$10 \mu \mathrm{M}$ DCFH-DA at $37^{\circ} \mathrm{C}$ for 30 min according to the manufacturer's instructions. The samples were analyzed by flow cytometry (Gallios Flow Cytometer; Beckman Coulter). Data were analyzed using FlowJo software (FlowJo Co., Ashland, OR, USA). For each sample, 10,000 events were collected.

Analysis of intracellular glutathione (GSH) levels. GSH plays a critical role in cellular defenses against oxidative stress. The L-02 cells were cultured in a 6-well plate for $24 \mathrm{~h}$ and then pre-treated with various concentrations of Q7R $(0,50,100$ and $200 \mu \mathrm{M})$. After $30 \mathrm{~min}$, GCDC $(100 \mu \mathrm{M})$ was added to the medium followed by and incubation at $37^{\circ} \mathrm{C}$ for $4 \mathrm{~h}$. Following incubation, the assay for GSH was performed using a GSH detection kit (Beyotime) according to the manufacturer's recommendations. The GSH level was analyzed by microplate reader (Mk3; Thermo Labsystems).

Mitochondrial membrane potential $(\Delta \psi m)$ assay. The $\Delta \psi \mathrm{m}$ was determined by the mean fluorescence intensity of rhodamine 123 (Rh123; Sigma). The L-02 cells ( $1 \times 10^{6}$ cells/well) were cultured in a 6 -well plate for $24 \mathrm{~h}$. Following treatment as described in above, the treated cells were collected and resuspended at a concentration of $1 \times 10^{5}$ cells $/ \mathrm{ml}$ in PBS. Rh123 $(5 \mu \mathrm{g} / \mathrm{ml})$ was added to the cells, followed by an incubation for $30 \mathrm{~min}$ prior to analysis under a fluorescence microscope (Nikon TE2000).

Analysis of the concentration of intracellular $\mathrm{Ca}^{2+}$ by laser scanning confocal microscopy. The L-02 cells $\left(1 \times 10^{6}\right.$ cells/ well) were added to each culture dish with coverslips for $24 \mathrm{~h}$ and the cells were then pre-treated with various concentra- tions of Q7R $(0,50,100$ and $200 \mu \mathrm{M})$. After $30 \mathrm{~min}, \mathrm{GCDC}$ $(100 \mu \mathrm{M})$ was added to the medium followed by incubation at $37^{\circ} \mathrm{C}$ for $24 \mathrm{~h}$. The cultured L-02 cells were loaded with $\mathrm{Ca}^{2+}$ indicator dye by incubating the culture dish in standard solution supplemented with $5 \mu \mathrm{M}$ Fluo-3-AM (Beyotime) for $50 \mathrm{~min}$ at room temperature. For measuring alterations in the intracellular $\mathrm{Ca}^{2+}$ concentration, a confocal laser-scanning microscope (Leica TCS SP5) was used. Fluo-3 was excited at the $488 \mathrm{~nm}$ line of an argon laser and the fluorescence was measured at an emission wavelength $>510 \mathrm{~nm}$ selected with a longpass filter. An oil immersion objective (Zeiss x16, NA 0.5) was used in all the experiments. Analysis of confocal images was performed using analysis software.

Statistical analysis. All values were expressed as the means \pm SD of 3 independent determinations. All experiments were carried out at least 3 times, each time with 3 or more independent observations. Statistical analyses were carried out using SPSS 16.0 software. The statistical significance of differences between the mean values was analyzed by one-way ANOVA followed by the Student-Newman-Keuls test. P-values $<0.05$ were considered to indicate statistically significant differences.

\section{Results}

Cell viability. GCDC at $100 \mu \mathrm{M}$ reduced the viability of L-02 cells, whereas pre-treatment with various concentrations of Q7R (50, 100 and $200 \mu \mathrm{M})$ for 30 min significantly ameliorated the GCDC-induced reduction in the viability of L-02 cells in a concentration-dependent manner (Fig. 2). 


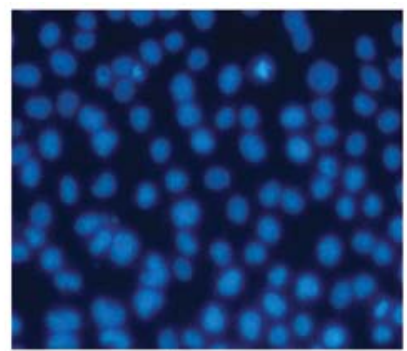

Control

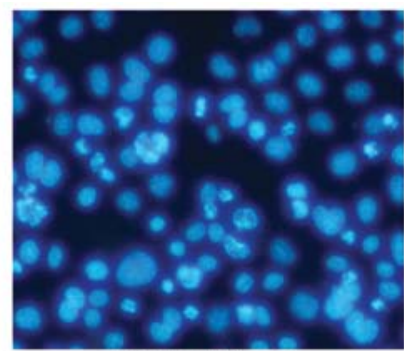

$\operatorname{GCDC}(100 \mu \mathrm{M})$

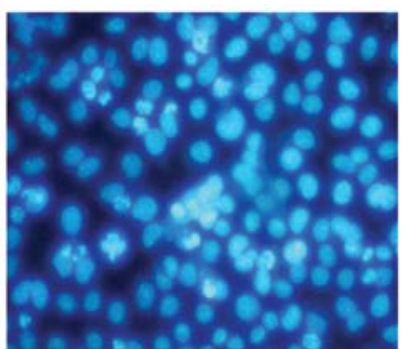

$\operatorname{GCDC}(100 \mu \mathrm{M})+\mathrm{Q7R}(50 \mu \mathrm{M})$

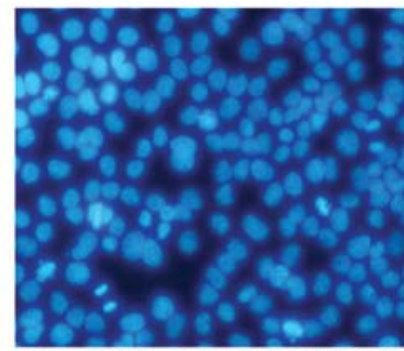

GCDC $(100 \mu \mathrm{M})+$ Q7R $(100 \mu \mathrm{M})$

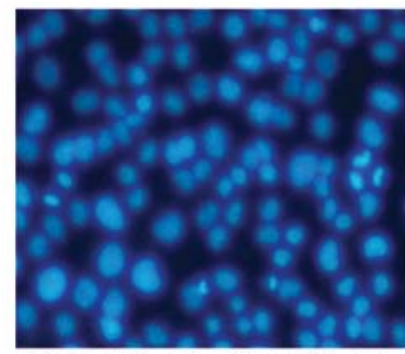

$\operatorname{GCDC}(100 \mu \mathrm{M})+\mathrm{Q} 7 \mathrm{R}(200 \mu \mathrm{M})$

Figure 3. Effects of quercetin 7-rhamnoside (Q7R) on glycochenodeoxycholic acid (GCDC)-induced L-02 cell apoptosis evaluated by Hoechst 33258 staining. The images shown are representative of 3 experiments. Magnification, $x 400$.
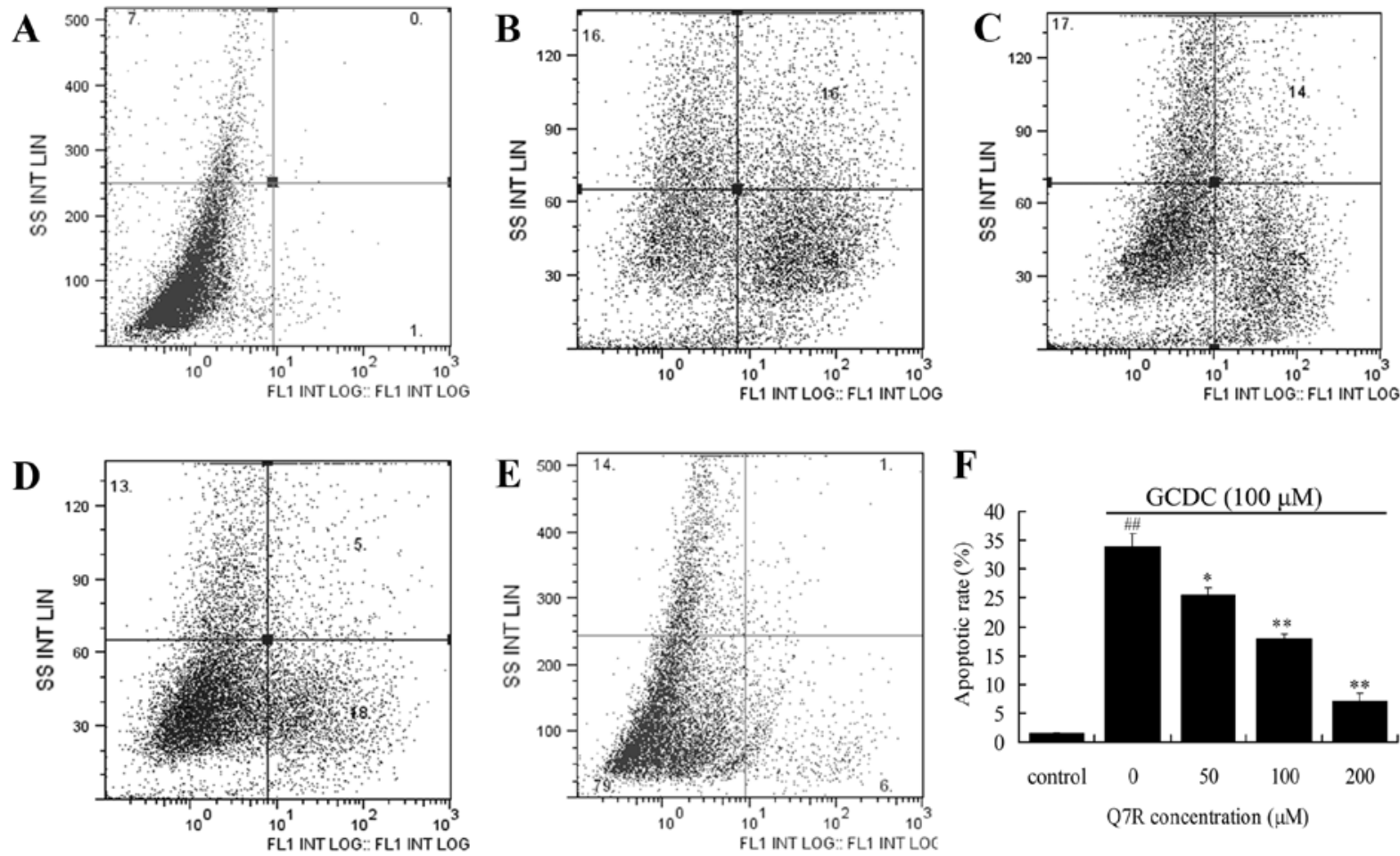

Figure 4. Effects of quercetin 7-rhamnoside (Q7R) on glycochenodeoxycholic acid (GCDC)-induced L-02 cell apoptosis evaluated by flow cytometry after Annexin V-FITC/PI staining. (A) Control cells. (B) Cells treated with GCDC $(100 \mu \mathrm{M})$ alone. (C) Cells pre-treated with Q7R $(50 \mu \mathrm{M})$ and then treated with GCDC $(100 \mu \mathrm{M})$. (D) Cells pre-treated with Q7R $(100 \mu \mathrm{M})$ and then treated with GCDC $(100 \mu \mathrm{M})$. (E) Cells pre-treated with Q7R $(200 \mu \mathrm{M})$ and then treated with GCDC $(100 \mu \mathrm{M})$. (F) The apoptotic rate in L-02 cells assessed by flow cytometry after Annexin V-FITC/PI staining. Shifts from no apoptosis (control) (bottom left quadrants) to early (bottom right quadrants) and late apoptosis (upper right quadrants) are clearly evident in the dot plots Each value represents the mean \pm SD of 3 individual experiments. ${ }^{\# \#} \mathrm{P}<0.01$ compared to control cells. ${ }^{*} \mathrm{P}<0.05,{ }^{* *} \mathrm{P}<0.01$ compared to cells treated with GCDC alone. The images shown are representative of 3 experiments.

Detection of apoptosis by Hoechst 33258 staining and Annexin V-FITC/PI double staining. The Hoechst 33258 dye stains the condensed chromatin of apoptotic cells more brightly than the chromatin of normal cells. A morphological observation of the L-02 cells indicated that the control L-02 cells had regular and round-shaped nuclei, revealed by nuclear staining with Hoechst 33258 (Fig. 3). By contrast, condensation and fragmentation of the nuclei, characteristic of apoptotic 

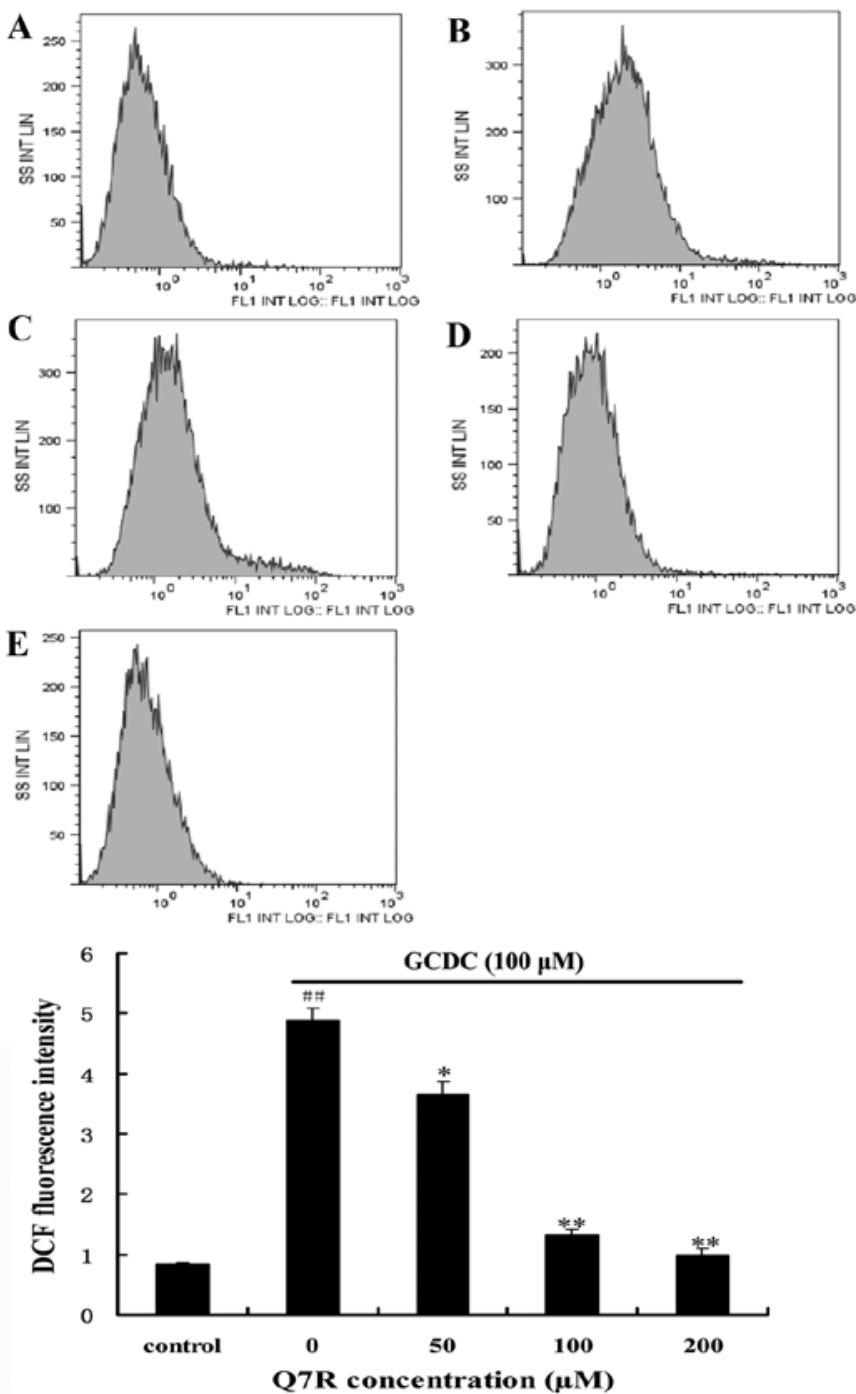

Figure 5. Flow cytometric analysis of the intracellular reactive oxygen species (ROS) levels in L-02 cells. (A) Control cells. (B) Cells treated with glycochenodeoxycholic acid (GCDC) $(100 \mu \mathrm{M})$ alone. (C) Cells pre-treated with quercetin 7-rhamnoside (Q7R) $(50 \mu \mathrm{M})$ and then treated with GCDC $(100 \mu \mathrm{M})$. (D) Cells pre-treated with Q7R $(100 \mu \mathrm{M})$ and then treated with GCDC $(100 \mu \mathrm{M})$. (E) Cells pre-treated with Q7R $(200 \mu \mathrm{M})$ and then treated with GCDC $(100 \mu \mathrm{M})$. Data shown are representative of 3 experiments. Each value represents the mean $\pm \mathrm{SD}$ of 3 separate experiments. ${ }^{\# \prime} \mathrm{P}<0.01$ compared to control cells. ${ }^{*} \mathrm{P}<0.05,{ }^{* *} \mathrm{P}<0.01$ compared to cells treated with GCDC alone.

cells were evident in the L-02 cells treated with GCDC. On the other hand, the number of apoptotic cells was significantly reduced in the cells exposed to Q7R $(50,100$ and $200 \mu \mathrm{M})$ in a concentration-dependent manner.

The occurrence of apoptosis was further confirmed by Annexin V/PI double staining. The apoptosis of the L-02 cells was observed after $24 \mathrm{~h}$ of exposure to GCDC. Fig. 4 shows the extent of apoptosis of the L-02 cells incubated with $100 \mu \mathrm{M}$ GCDC with or without Q7R. Shifts from no apoptosis (control) (bottom left quadrants) to early (bottom right quadrants) and late apoptosis (upper right quadrants) are clearly evident in the dot plots. The numbers of total (early + late) apoptotic cells were markedly enhanced following treatment with $100 \mu \mathrm{M}$ GCDC after $24 \mathrm{~h}$. On the other hand, pre-treatment with

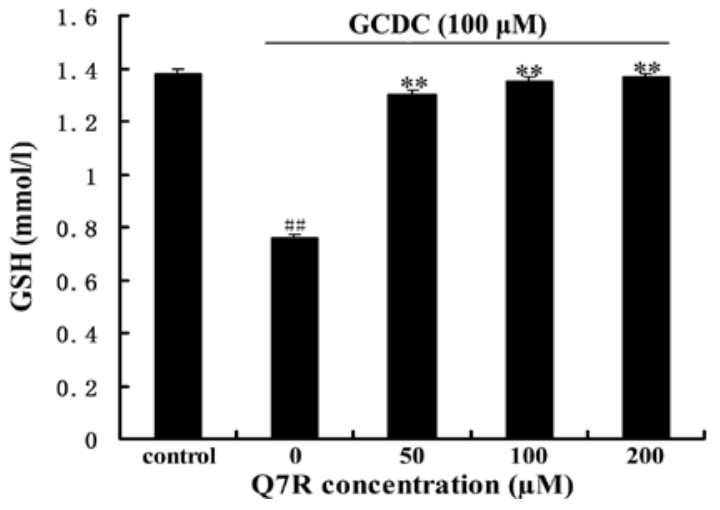

Figure 6. Effects of quercetin 7-rhamnoside (Q7R) on the glutathione (GSH) levels in L-02 cells. Values are expressed as the means \pm SD of 3 separate experiments. ${ }^{\# \#} \mathrm{P}<0.01$ compared to control cells. ${ }^{* *} \mathrm{P}<0.01$ compared to cells treated with glycochenodeoxycholic acid (GCDC) alone.

various concentrations of Q7R (50, 100 and $200 \mu \mathrm{M})$ significantly reduced the percentage of apoptotic L-02 cells.

Analysis of intracellular ROS levels by flow cytometry. Treatment with $100 \mu \mathrm{M}$ GCDC for $12 \mathrm{~h}$ increased ROS production in the L-02 cells (Fig. 5). In addition, the results revealed a significant decrease in intracellular ROS after $12 \mathrm{~h}$ of co-incubation with various concentrations of Q7R $(50,100$ and $200 \mu \mathrm{M})$.

Analysis of intracellular GSH levels. The intracellular concentration of GSH was determined to elucidate the mechanisms through which Q7R exerts its antioxidant effects. Fig. 6 demonstrates that the intracellular GSH content in the L-02 cells was markedly reduced following exposure to $100 \mu \mathrm{M}$ GCDC for $24 \mathrm{~h}$, whereas the reduction in GSH content was significantly inhibited following pre-treatment with various concentrations of Q7R (50, 100 and $200 \mu \mathrm{M})$.

$\Delta \psi m$ assay. Mitochondrial permeability transition (MPT) has been shown to play a key role in bile acid-induced hepatocyte necrosis, as well as other models of cellular apoptosis. As a consequence of MPT, the $\Delta \psi \mathrm{m}$ collapses, thereby uncoupling the respiratory chain and inhibiting adenosine triphosphate (ATP) biosynthesis during cell apoptosis. The fluorescent dye, $\mathrm{Rh} 123$, is used to measure $\Delta \psi \mathrm{m}$. Treatment with $100 \mu \mathrm{M}$ GCDC for $24 \mathrm{~h}$ significantly decreased the $\Delta \psi \mathrm{m}$ in the L-02 cells when compared with the control cells, whereas the reduction in $\Delta \psi \mathrm{m}$ was significantly inhibited following pretreatment with various concentrations of Q7R $(50,100$ and $200 \mu \mathrm{M}$ ) in a concentration-dependent manner (Fig. 7).

Analysis of the concentration of intracellular $\mathrm{Ca}^{2+}$ by laser scanning confocal microscopy. It is well known that the increase in the intracellular free $\mathrm{Ca}^{2+}$ concentration is associated with the initiation of apoptosis. The ability of GCDC $(100 \mu \mathrm{M})$ to induce intracellular $\mathrm{Ca}^{2+}$ accumulation in the L-02 cells was investigated in this experiment. To reveal the alterations in the intracellular $\mathrm{Ca}^{2+}$ concentration, living cells were observed under a confocal microscope using Fluo-3 AM as an indicator. Fig. 8 illustrates that the addition of GCDC 


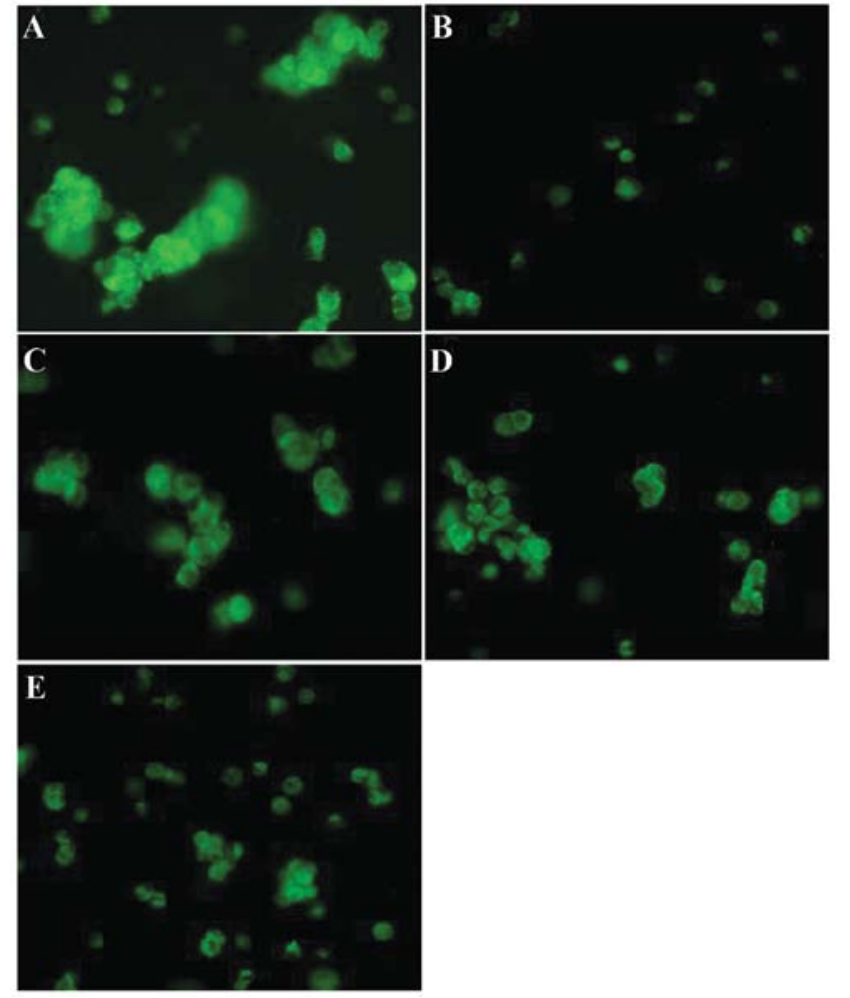

Figure 7. Effects of quercetin 7-rhamnoside (Q7R) on mitochondrial membrane potential in L-02 cells. (A) Control cells. (B) Cells treated with glycochenodeoxycholic acid (GCDC) $(100 \mu \mathrm{M})$ alone. (C) Cells pre-treated with Q7R $(50 \mu \mathrm{M})$ and then treated with GCDC $(100 \mu \mathrm{M})$. (D) Cells pretreated with Q7R $(100 \mu \mathrm{M})$ and then treated with GCDC $(100 \mu \mathrm{M})$. (E) Cells pre-treated with Q7R $(200 \mu \mathrm{M})$ and then treated with GCDC $(100 \mu \mathrm{M})$. The images shown are representative of 3 experiments. Magnification, $\mathrm{x} 400$.

$(100 \mu \mathrm{M})$ to the cell medium induced a significant increase in the intracellular $\mathrm{Ca}^{2+}$ concentration, whereas the addition of various concentrations of Q7R $(50,100$ and $200 \mu \mathrm{M})$ to the cell culture inhibited this increase in a concentrationdependent manner.

\section{Discussion}

Hepatocyte damage by toxic bile acids is considered to represent a major event in the progression of cholestatic liver disease (22). Toxic bile acids, particularly GCDC, which is the predominant dihydroxy bile acid in cholestatic patients and has been held responsible for cholestasis-associated liver injury, induce hepatocellular apoptosis, thereby providing a cellular mechanism for bile acid-mediated liver injury and fibrogenesis (23). A number of studies have attempted to elucidate the intracellular mechanisms behind the GCDC-induced apoptotic form of hepatocyte death $(8,24)$. GCDC has been reported to induce apoptosis by activating the death receptor or extrinsic pathway, through the mitochondrial or intrinsic pathway and by causing endoplasmic reticulum stress $(8,25)$. In this study, hepatocyte apoptosis induced by GCDC (100 $\mu \mathrm{M})$ was used to represent a model for human cholestasis (26). The results revealed that GCDC $(100 \mu \mathrm{M})$ induced higher degrees of cell injury and apoptosis in the L-02 cells, while Q7R reversed the GCDC-induced reduction in cell viability. Furthermore, using Hoechst 33258 and Annexin V-FITC/PI staining
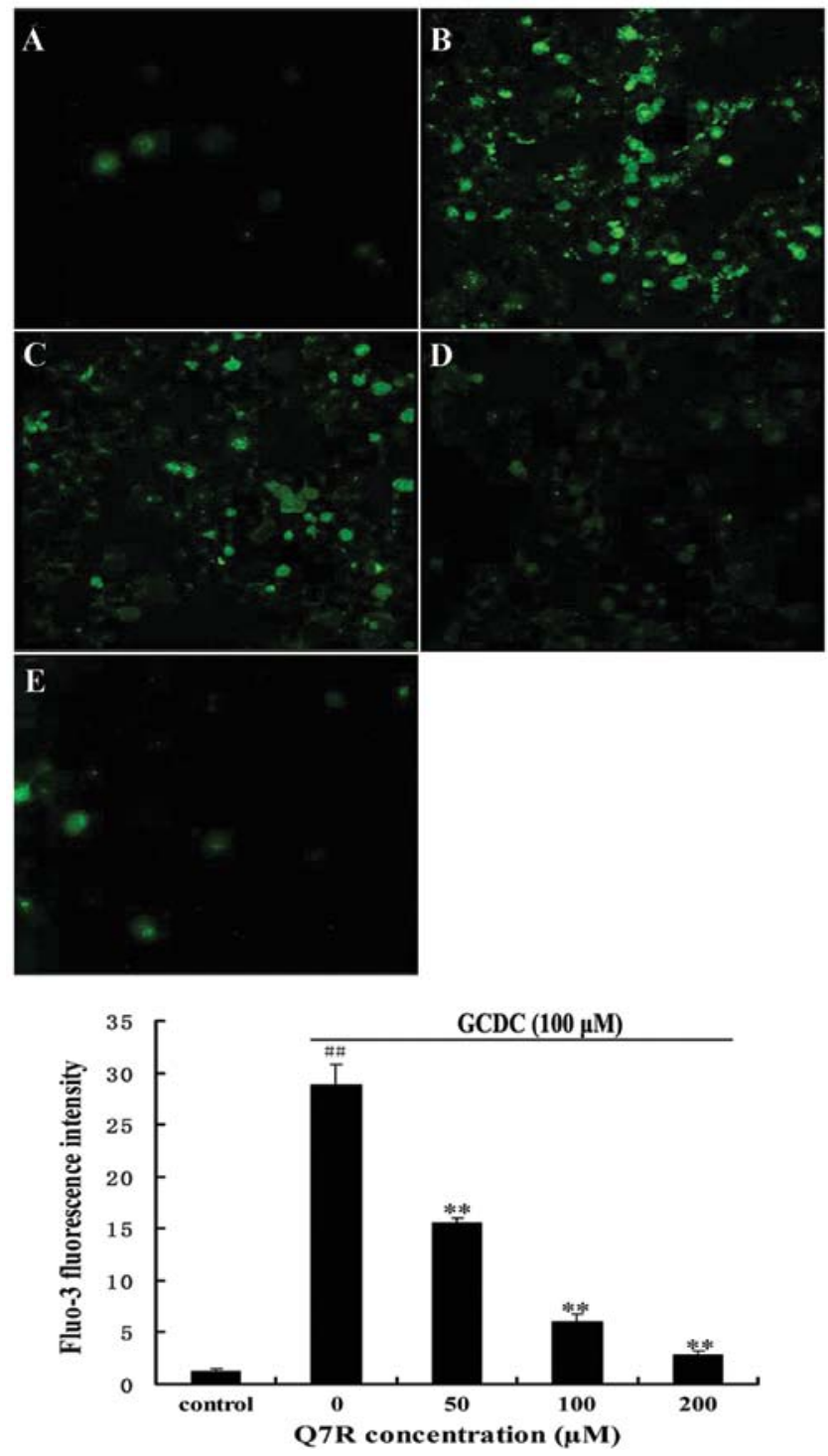

Figure 8. Effects of quercetin 7-rhamnoside (Q7R) on intracellular $\mathrm{Ca}^{2+}$ concentration. (A) Control cells. (B) Cells treated with glycochenodeoxycholic acid (GCDC) $(100 \mu \mathrm{M})$ alone. (C) Cells pre-treated with Q7R $(50 \mu \mathrm{M})$ and then treated with GCDC $(100 \mu \mathrm{M})$. (D) Cells pre-treated with Q7R $(100 \mu \mathrm{M})$ and then treated with GCDC $(100 \mu \mathrm{M})$. (E) Cells pre-treated with Q7R $(200 \mu \mathrm{M})$ and then treated with GCDC $(100 \mu \mathrm{M})$. Each value represents the mean \pm SD of 3 individual experiments. ${ }^{\# \#} \mathrm{P}<0.01$ compared to control cells. ${ }^{* *} \mathrm{P}<0.01$ compared to cells treated with GCDC alone. The images shown are representative of 3 experiments. Magnification, $\mathrm{x} 400$.

assays, to our knowledge, this study showed for the first time that apoptosis induced by GCDC $(100 \mu \mathrm{M})$ was attenuated following treatment with various effective concentrations of Q7R (Figs. 2 and 4). Thus, the mechanisms involved in this anti-apoptotic effect were investigated.

Oxidative stress has been implicated in the pathogenesis of hepatic injury during cholestasis in rats and humans and can initiate hepatocyte apoptosis by inducing DNA damage and upregulating the expression of transmembrane proteins, such as FasL and Fas $(4,8,27)$. Hydrophobic bile acids are believed to cause hepatocellular necrosis and apoptosis partly through the induction of MPT and the generation of ROS in hepatic mitochondria and hepatocytes, leading to the depletion of antioxidant defenses $(13,28,29)$. Intracellular ROS generation by mitochondria appears to be a primary factor 
or a mandatory signal in GCDC-induced hepatocyte apoptosis (30). The results from the present study demonstrated that Q7R effectively protected the L-02 cells against oxidative damage caused by GCDC, as indicated by the suppression of ROS formation. These data strongly suggest that Q7R plays an important protective role against ROS overproduction induced by GCDC in hepatocytes.

GSH is a tripeptide ( $\gamma$-glutamylcysteinyl-glycine) which directly plays a major antioxidant role in scavenging ROS through the enzymes, GSH peroxidase and GSSG reductase, and maintaining the intracellular redox state (31). GSH has been implicated in the protection against the induction of apoptotic and necrotic cell death in a variety of cell types $(32,33)$. The results from the present study indicated that Q7R markedly increased GSH levels in the presence of GCDC. It is speculated that reduced hepatocyte damage with Q7R is associated with diminished oxidative stress and reversed levels of GSH.

Mitochondrial dysfunction can occur in death-receptormediated apoptosis, particularly the so called 'type II cells', such as hepatocytes (34). Mitochondrial membrane perturbations are important features of bile acid-induced apoptosis. Inhibitors of MPT suppress GCDC-induced rat hepatocyte apoptosis (4). Hydrophobic bile acids directly induce mitochondrial membrane potential depolarization in hepatocytes (6). Our results revealed that $100 \mu \mathrm{M}$ GCDC induced damage to the mitochondrial membrane and decreased $\Delta \psi \mathrm{m}$ in the L-02 cells, whereas Q7R attenuated mitochondrial membrane perturbation.

Intracellular calcium is a universal messenger in cells. It regulates physiological processes and is involved in pathological processes, such as cell injury/death. Accumulating evidence demonstrates the role of intracellular $\mathrm{Ca}^{2+}$ deregulation in the induction of apoptosis. Calcium toxicity is considered to be an important factor contributing to bile acid-induced cellular damage (35). An increase in the cytosolic free calcium concentration induced by hydrophobic bile acids is considered an important permissive factor that allows oxidave stress to open the permeability pore (36). The cytosolic calcium-protein kinase $\mathrm{C}$ (PKC) intracellular signaling pathway is an important signaling pathway that regulates several key liver functions, while abnormalities in this pathway have been implicated in liver cell injury (37). The present study demonstrated that the GCDC-induced increase in the intracellular $\mathrm{Ca}^{2+}$ concentration was reduced following pre-treatment with Q7R, suggesting that Q7R protects hepatocytes from apoptosis by maintaining the intracellular free $\mathrm{Ca}^{2+}$ homeostasis.

On the basis of the results presented in this study, to our knowledge, we demonstrate for the first time that Q7R exerts protective effects against GCDC-induced apoptosis in L-02 cells at least in part by decreasing intracellular ROS levels, ameliorating GSH depletion, maintaining $\Delta \psi \mathrm{m}$ and intracellular free $\mathrm{Ca}^{2+}$ homeostasis.

\section{Acknowledgements}

The authors gratefully acknowledge the financial support provided by the Program for the Guangdong Province Science and Technology Department (grant no. 2011B050300010).

\section{References}

1. Jones BA and Gores GJ: Physiology and pathophysiology of apoptosis in epithelial cells of the liver, pancreas, and intestine. Am J Physiol 273: G1174-G1188, 1997.

2. Oh SH, Yun KJ, Nan JX, Sohn DH and Lee BH: Changes in expression and immunolocalization of protein associated with toxic bile salts-induced apoptosis in rat hepatocytes. Arch Toxicol 77: 110-115, 2003.

3. Rodrigues CM and Steer CJ: Mitochondrial membrane perturbations in cholestasis. J Hepatol 32: 135-141, 2000.

4. Yerushalmi B, Dahl R, Devereaux MW, Gumpricht E and Sokol RJ: Bile acid-induced rat hepatocyte apoptosis is inhibited by antioxidants and blockers of the mitochondrial permeability transition. Hepatology 33: 616-626, 2001.

5. Guicciardi ME and Gores GJ: Apoptosis: a mechanism of acute and chronic liver injury. Gut 54: 1024-1033, 2005.

6. Palmeira CM and Rolo AP: Mitochondrially-mediated toxicity of bile acids. Toxicology 203: 1-15, 2004.

7. Galle PR, Theilmann L, Raedsch R, Otto G and Stiehl A: Ursodeoxycholate reduces hepatotoxicity of bile salts in primary human hepatocytes. Hepatology 12: 486-491, 1990.

8. Perez MJ and Briz O: Bile-acid-induced cell injury and protection. World J Gastroenterol 15: 1677-1689, 2009.

9. Patel T, Bronk SF and Gores GJ: Increases of intracellular magnesium promote glycodeoxycholate-induced apoptosis in rat hepatocytes. J Clin Invest 94: 2183-2192, 1994.

10. Kwo P, Patel T, Bronk SF and Gores GJ: Nuclear serine protease activity contributes to bile acid-induced apoptosis in hepatocytes. Am J Physiol 268: G613-G621, 1995.

11. Billington D, Evans CE, Godfrey PP and Coleman R: Effects of bile salts on the plasma membranes of isolated rat hepatocytes. Biochem J 188: 321-327, 1980.

12. Sokol RJ, Straka MS, Dahl R, et al: Role of oxidant stress in the permeability transition induced in rat hepatic mitochondria by hydrophobic bile acids. Pediatr Res 49: 519-531, 2001.

13. Maillette de Buy Wenniger L and Beuers U: Bile salts and cholestasis. Dig Liver Dis 42: 409-418, 2010.

14. Perez MJ, Macias RI and Marin JJ: Maternal cholestasis induces placental oxidative stress and apoptosis. Protective effect of ursodeoxycholic acid. Placenta 27: 34-41, 2006.

15. Wang N,Li P, Wang Y, et al: Hepatoprotective effect of Hypericum japonicum extract and its fractions. J Ethnopharmacol 116: 1-6, 2008.

16. Su J, Fu P, Shen Y, et al: Simultaneous analysis of flavonoids from Hypericum japonicum Thunb.ex Murray (Hypericaceae) by HPLC-DAD-ESI/MS. J Pharm Biomed Anal 46: 342-348, 2008.

17. Choi HJ, Kim JH, Lee CH, Ahn YJ, Song JH, Baek SH and Kwon DH: Antiviral activity of quercetin 7-rhamnoside against porcine epidemic diarrhea virus. Antiviral Res 81: 77-81, 2009.

18. Song JH, Shim JK and Choi HJ: Quercetin 7-rhamnoside reduces porcine epidemic diarrhea virus replication via independent pathway of viral induced reactive oxygen species. Virol J 8: 460, 2011.

19. Awaad AS, Maitland DJ and Soliman GA: Hepatoprotective activity of Schouwia thebica webb. Bioorg Med Chem Lett 16: 4624-4628, 2006.

20. Rathee P, Rathee D, Rathee D and Rathee S: In-vitro cytotoxic activity of $\beta$-Sitosterol triacontenate isolated from Capparis decidua (Forsk.) Edgew. Asian Pac J Trop Med 5: 225-230, 2012.

21. Vermes I, Haanen C, Steffens-Nakken H and Reutelingsperger C: A novel assay for apoptosis. Flow cytometric detection of phosphatidylserine expression on early apoptotic cells using fluorescein labelled Annexin V. J Immunol Methods 184: 39-51, 1995.

22. Hofmann AF: Cholestatic liver disease: pathophysiology and therapeutic options. Liver 22: 14-19, 2002.

23. Rust C, Wild N, Bernt C, Vennegeerts T, Wimmer R and Beuers U: Bile acid-induced apoptosis in hepatocytes is caspase-6-dependent. J Biol Chem 284: 2908-2916, 2009.

24. Lee TY, Chen FY, Chang HH and Lin HC: The effect of capillarisin on glycochenodeoxycholic acid-induced apoptosis and heme oxygenase-1 in rat primary hepatocytes. Mol Cell Biochem 325: 53-59, 2009.

25. Wang K, Brems JJ, Gamelli RL and Holterman AX: Survivin signaling is regulated through nuclear factor-kappa B pathway during glycochenodeoxycholate-induced hepatocyte apoptosis. Biochim Biophys Acta 1803: 1368-1375, 2010. 
26. Graf D, Kurz AK, Reinehr R, Fischer R, Kircheis G and Häussinger D: Prevention of bile acid-induced apoptosis by betaine in rat liver. Hepatology 36: 829-839, 2002.

27. Kaplowitz N: Mechanisms of liver cell injury. J Hepatol 32 (Suppl 1): S39-S47, 2000.

28. Kim JS, He L and Lemasters JJ: Mitochondrial permeability transition: a common pathway to necrosis and apoptosis. Biochem Biophys Res Commun 304: 463-470, 2003.

29. Sokol RJ, Dahl R, Devereaux MW, Yerushalmi B, Kobak GE and Gumpricht E: Human hepatic mitochondria generate reactive oxygen species and undergo the permeability transition in response to hydrophobic bile acids. J Pediatr Gastroenterol Nutr 41: 235-243, 2005.

30. Sokol RJ, Winklhofer-Roob BM, Devereaux MW and McKim JM Jr: Generation of hydroperoxides in isolated rat hepatocytes and hepatic mitochondria exposed to hydrophobic bile acids. Gastroenterology 109: 1249-1256, 1995.

31. Meister A: Glutathione metabolism and its selective modification. J Biol Chem 263: 17205-17208, 1988.
32. Fernandes RS and Cotter TG: Apoptosis and necrosis: intracellular levels of glutathione influence mode of cell death. Biochem Pharmacol 48: 675-681, 1994.

33. Ben-Yoseph O, Boxer PA and Ross BD: Assessment of the role of the glutathione and pentose phosphate pathways in the protection of primary cerebrocortical cultures from oxidative stress. J Neurochem 66: 2329-2337, 1996.

34. Scaffidi C, Fulda S, Srinivasan A, et al: Two CD95 (APO-1/Fas) signaling pathways. EMBO J 17: 1675-1687, 1998.

35. Venglovecz V, Rakonczay Z Jr, Ozsvári B, et al: Effects of bile acids on pancreatic ductal bicarbonate secretion in guinea pig. Gut 57: 1102-1112, 2008.

36. Anwer MS, Engelking LR, Nolan K, Sullivan D, Zimniak P and Lester R: Hepatotoxic bile acids increase cytosolic $\mathrm{Ca}^{2+}$ activity of isolated rat hepatocytes. Hepatology 8: 887-891, 1988.

37. Berridge MJ: Inositol trisphosphate and calcium signalling mechanisms. Biochim Biophys Acta 1793: 933-940, 2009. 